\title{
Desfase estructural y la emergencia de los intelectuales indígenas bolivianos
}

\section{Carmen Rosa Rea Campos*}

Perfiles Latinoamericanos, $24(48)$

2016 | pp. 33-60

DOI: $10.18504 / \mathrm{pl} 2448-002-2016$

\section{Resumen}

Retomando el concepto bourdiano de desfase estructural, este artículo analiza la génesis de los intelectuales indígenas en Bolivia a partir de la década de los sesenta y el papel que han desempeñado en la historia reciente de los movimientos indígenas, en tanto productores de sentido y agentes en disputa por la legitimidad de su condición y su práctica intelectual. Dar cuenta de ambos aspectos permite comprender tanto la particularidad de los resultados del último ciclo de protestas (1999-2005) protagonizado por los movimientos indígenas, como las transformaciones políticas que experimenta Bolivia desde entonces.

\begin{abstract}
Retaking Bourdieu's concept of desfase estructural, this article analyzes the genesis of indigenous intellectuals in Bolivia from the sixties and the role they have played in the recent history of indigenous movements, as producers of meaning and agents in dispute by the legitimacy of their status and intellectual practice. Both aspects allow to understanding both the particularity of the results of the last cycle of protests (1999-2005) starring indigenous movements as political changes experiencing the Bolivian population, since.
\end{abstract}

Palabras claves: Bolivia, intelectuales indígenas, desfase estructural, campo intelectual, movimientos sociales.

Keywords: Bolivia, indigenous intellectuals, structural inconsistency, intellectual field, social movements.

* Doctora en Ciencia Social con especialidad en Sociología. Profesora Investigadora de la División de Ciencias Sociales y Humanidades, Universidad de Guanajuato. Campus León. 
Todos los hombres son intelectuales [...] pero no todos los hombres tienen en la sociedad la función de intelectuales...

Antonio Gramsci

A

más de diez años del último ciclo de protestas sociales en Bolivia, el cual fue encabezado por diferentes sectores sociales (indígenas, campesinos, obreros, entre otros) y que culminó con el triunfo electoral del Movimiento al Socialismo (MAS) en 2005 con un voto mayoritario del 53.72\% - mismo que ha ido en incremento en los procesos electorales del 2009 y 2014 garantizando el mandato de Evo Morales hasta el 2020_, todavía queda abierta la pregunta sobre los factores explicativos que originaron ese ciclo de protestas.

Gran parte de los estudios se han concentrado en los factores estructurales, ya políticos, como las crisis de ingobernabilidad de arriba hacia abajo o de abajo hacia arriba (Lazarte, 2005, 2007; Mansilla, 2003; Toranzo, 2009); ya económicos y sociales, como la agudización de las pobreza y la ampliación de la brecha de desigualdad producto del modelo de acumulación neoliberal (Tapia, Gutiérrez \& García, 2001; García, 2003, 2005; Prada, 2003; Mamani, 2004). Pero sean políticas o económicas, estos autores señalan que tales crisis provocaron el hartazgo de los indígenas y su necesidad de justicia. Por ejemplo, Lazarte argumenta que la "ingobernabilidad" política desde arriba — expresada en corrupción, prebendas y pugnas permanentes entre la clase política- contribuyó al "sentimiento de impotencia", de rabia contenida, "de injusticia vivida por los pobres", los cuales comprendieron finalmente que las políticas neoliberales solo habían beneficiado a los más ricos y que, por tanto, la oportunidad para estallar en conflicto social era inevitable (Lazarte, 2005: p. 331). En la misma línea argumentativa van aquellos que sostienen los fundamentos materiales de la crisis que experimentó Bolivia a principios del siglo $\mathrm{xx}$, al afirmar que la intensificación de la expropiación y explotación de la economía de familias campesinas, de la fuerza laboral indígena, más la precariedad del mercado laboral y la concentración de la riqueza en un pequeño sector del capitalismo productivo y financiero en detrimento del empobrecimiento de los sectores indígenas, fueron el detonante de los acontecimientos suscitados en tal periodo (García et al., 2001; Tapia, Gutiérrez \& García, 2000; García, 2003).

Aunque las afirmaciones desde estas dos perspectivas son correctas tienden a caer en una mirada conductista de la acción colectiva pues, visto así, la acción colectiva indígena resulta una reacción ante los estímulos externos, lo que poco atiende el papel más activo de otros factores internos al movimiento, como es el caso de los intelectuales indígenas. De estos últimos tratan estas páginas, de su génesis, de aquello social que explica por qué algunos indígenas asumen 
un papel intelectual. Explicar este proceso (sin negar los factores estructurales arriba citados) ayuda a comprender el curso de la historia del movimiento indígena boliviano a partir de los setenta, la particularidad de los resultados en el último ciclo de protestas (1999-2005) y el periodo de transformaciones que desde entonces ha experimentado Bolivia.

La hipótesis que se sostiene en este artículo es que sociológicamente la emergencia de este agente se explica por el desfase estructural que experimentaron ciertos individuos de origen indígena, entre las transformaciones de sus expectativas subjetivas que supuso acceder a un capital que carecían (el escolar) y las escasas posibilidades de cambiar sus posiciones sociales y la relación con el otro dominante (el no indígena). Es decir, el acceso a la educación que las poblaciones indígenas bolivianas experimentaron desde fines de la década de 1960 , no solo produjo un proceso de asimilación cultural ${ }^{1}$ encaminado a reproducir las relaciones de dominación, sino que tal apertura tuvo como efecto no esperado la vacilación de uno de los fundamentos de la sumisión al orden social: la desposesión de los sujetos subalternos (Nordmann, 2010). Partir de esta tesis supone cuestionar la relación teleológica que se suele establecer entre el origen étnico, la labor académica y el discurso político, para asignar a ciertos individuos de origen étnico la categoría social de intelectuales indígenas.

Dicho lo anterior, inicio el artículo retomando el concepto gramsciano de intelectual orgánico para discutir las limitaciones que supone atribuir esta categoría analítica (intelectuales indígenas) a sujetos de origen étnico que accedieron a una educación formal y que se desempeñan en ámbitos de la academia formal. En un segundo y tercer apartado, argumento que tal relación existe pero que esta no se basa ni en una relación teleológica entre origen étnico-capital escolardiscurso, ni en la labor academicista que desempeñan, sino que ello es resultado de un proceso sociológico de ruptura que esos intelectuales experimentaron en algún momento de sus trayectorias individuales. En un cuarto apartado retomo el ciclo de protestas de principios del año 2000 para argumentar cómo el escenario de disputa política se constituyó, a la vez, en un escenario de disputa en el campo intelectual boliviano, donde lo que estaba en juego era la legitimidad de la práctica intelectual y la validez "objetiva" en la interpretación de las cosas (la realidad social), lo cual implicó para algunos el paso del "intelectual orgánico" al "académico intelectual".

1 Promover el acceso de la educación básica para la población indígena como política de Estado fue una de las estrategias de las élites gobernantes nacionalistas a mediados del siglo xx, en su afán de homogeneizar culturalmente al país — caracterizado por su abigarramiento cultural y estructural—, para dotarle de una identidad nacional con la pretensión de superar su atraso económico. Este fenómeno tuvo su réplica en otros países con mayorías indígenas como México, Ecuador, Perú, Guatemala. 


\section{¿Por qué hablar de intelectuales indígenas?}

Hablar de los intelectuales y su relación con la acción política, lo mismo que retomar el concepto de "intelectual orgánico" formulado por Antonio Gramsci es complicado, pues hoy más que nunca se propende a pensar que las fronteras entre el intelectual, el poder y la política se han tornado un poco más nítidas que antes, tras la derrota del socialismo, la caída del muro de Berlín y el fracaso de los grupos guerrilleros en América Latina, incluyendo la aparente "intrascendencia” actual — como efecto del aislamiento mediático—- del Ejército Zapatista de Liberación Nacional (eZLN) en México.

Sin embargo, para el caso que nos ocupa y en un contexto donde la labor académica o academicista se plantea como sinónimo de la función social de intelectual, es relevante recuperar el concepto gramsciano y su discusión sobre el intelectual orgánico. ${ }^{2} Y$ también es fundamental vincular tal discusión con los aportes de Bourdieu (1999b) sobre: 1) la noción de intelectual como una agente social ambiguo por los tipos de capitales a los que accede (económico, escolar, simbólico) y la posición que ocupa en el campo económico (dominante-dominado o dominado-dominante); 2) el concepto de campo social como espacio de lucha que permite definir y ubicar a este agente social en su condición de actor específico en disputa por los recursos escasos (la legitimidad del saber y de su práctica intelectual) no solo en el campo político sino también en el intelectual, y 3) el concepto de desfase estructural que, desde mi perspectiva, contribuye a desmitificar, desnaturalizar y reflexionar sobre el vínculo histórico entre el rol de intelectual y el origen étnico.

Quienes discuten sobre la categoría analítica de intelectual indígena, para designar con ella a ciertos individuos, comparten un punto de partida: que ciertos segmentos de la población indígena accedieron a la educación superior desde mediados del siglo xx (Zapata, 2008; Rappaport, 2007; Salazar, 2012). Se trata de una apertura que formó parte de las políticas asimilacionistas de los Estados-nación en distintos países de América Latina, en el afán de consolidar una identidad nacional por medio de la homogeneización cultural entre sus poblaciones culturalmente heterogéneas, más todavía en países con altos porcentajes de poblaciones indígenas, como México, Ecuador, Perú y Bolivia, para citar algunos. A partir de ello se suele asumir una relación mecánica entre el

2 Gramsci seńala que todo grupo social que surge sobre la base original de una función esencial en las relaciones de producción y que, por tanto, históricamente se encuentra en disposición de asumir el poder y la dirección de otras clases, establece orgánicamente uno o más tipos de intelectuales que dan homogeneidad económica, política y social a dicho grupo. Por ello define al intelectual orgánico como aquel "que emerge 'sobre el terreno a exigencia de una función necesaria en el campo de la producción económica” (Gramsci, 1967: pp. 21-22). 
origen étnico, el capital escolar y la función de intelectual, sobre todo cuando los sujetos proceden de algún grupo étnico. Esto es, que por haber accedido a una formación superior escolarizada un sujeto de origen indígena es "intelectual indígena”, más aún cuando la profesionalización se vincula con ámbitos disciplinarios de las ciencias sociales y humanidades. ${ }^{3}$ No niego que tal relación exista, pero es necesario discutirla, pues — retomando a Gramsci- si la condición de intelectual es generalizable a todos los hombres como una capacidad intrínseca de la condición humana, la función de intelectual — de producir discursos que influyen sobre la opinión pública posibilitando grados de homogeneidad política, económica y social de un grupo en particular - solo es desempeñada por algunos (Gramsci, 1967: p. 26). ${ }^{4}$ Por lo anterior, en el caso de los indígenas no los hace intelectual su condición de profesionalización escolarizada, ni su condición étnica los hace "intelectuales indígenas".

Rappaport y Zapata parten de la pregunta "¿qué es lo específico del intelectual indígena?", para argumentar que esa especificidad no radica en la procedencia u origen étnico de quienes son definidos como tales; aunque, argumentan, que para que alguien sea definido como "intelectual indígena" el origen étnico es un indicador imprescindible. Sin embargo, es importante subrayar que si el origen es un criterio ineludible no basta para que un individuo indígena asuma tal función. Rappaport y Zapata también señalan que aquello que hace a este agente social intelectual indígena, además del origen étnico y el capital escolar adquirido (títulos académicos), es, fundamentalmente, el discurso étnico desde donde producen conocimientos que pueden ser apropiados por los agentes sociales colectivos del mismo origen, sobre todo las organizaciones indígenas y los movimientos sociales. Es decir, en tanto intelectuales indígenas son intelectuales orgánicos —en el sentido gramsciano del término- cuyos conocimientos y discursos intentan impulsar la formulación de proyectos alternativos al discurso dominante nacional, basados en la valoración y legitimación de la diferencia y las particularidades étnicas (Rappaport, 2007; Zapata, 2008).

Puede que dichos indicadores (origen étnico, capital escolar y discurso) sean grosso modo los necesarios para definir a alguien como "intelectual indígena" y que su particularidad resida sobre todo en el discurso étnico que asume y construye. No obstante, llama la atención que ninguna de las autoras explica cómo se establece este vínculo entre la función de intelectual y el discurso étnico "alternativo" al discurso dominante, sobre todo si partimos del supuesto de que

3 Véanse los aportes de Salazar (2012), Zapata (2008) y Rappaport (2007).

4 Por lo anterior, en este escrito y siguiendo a Gramsci, el término intelectual indígena se utiliza para referir a quienes cumplen la función de intelectuales orgánicos. 
no hay una correlación directa entre este rol social (intelectual) y el origen étnico de quien lo asume. Por tanto, la pregunta continúa abierta: ¿cómo y en qué condiciones se establece la función de intelectual de los sujetos de origen étnico? Para explicarlo retomaré el concepto de desfase estructural, pues este permite evitar los determinismos que naturalizan aquello que es absolutamente social e histórico (el origen étnico, la adquisición de capital escolar y la función social). Al mismo tiempo, permite controlar la tendencia voluntarista en la que se cae cuando se dota al individuo de una capacidad autónoma sin estructuras que lo determinen.

\section{Correlación y ruptura entre disposiciones subjetivas y las posibilidades objetivas}

Uno de los argumentos por el cual Bourdieu ha sido catalogado como un teórico de la reproducción social radica en sostener que el habitus - ese dispositivo duradero de percepciones y esquemas de pensamiento estructurados y estructurantes - funciona como un principio de sumisión al orden social, pues se reproduce con pocos cambios a lo largo de las trayectorias individuales y a pesar de las transformaciones al nivel de las condiciones objetivas. Sin embargo, la efectividad del principio de sumisión al orden social solo es posible cuando se establece una concordancia entre los esquemas de la visión del mundo y la estructura del espacio social, entre las expectativas subjetivas y las probabilidades objetivas de los agentes, situación que hace que "más allá de los sueños y rebeliones los agentes tiendan a vivir conforme a su condición social"; incluso los deseos y la satisfacción que experimentan los agentes están adaptados a las posibilidades (objetivas) de realización (Bourdieu, 2011: p. 87; Bourdieu, 1999a: pp. 196-198). En esta concordancia, la educación desempeña un papel importante en espacios disciplinarios como la escuela, la familia, la iglesia o el ejército, pues estos, y sobre todo la escuela, constituyen espacios legitimadores de las jerarquías y posiciones sociales que ocupan los agentes sociales en contextos determinados.

Por esta concordancia entre expectativas subjetivas y oportunidades esperadas es posible comprender que, por ejemplo, a pesar de las movilizaciones indígenas a lo largo del siglo xx y que los indígenas campesinos fueron uno de los principales protagonistas de la Revolución Nacionalista de 1952, indígenas y campesinos se mantuvieron como sujetos dominados (subalternos), en términos económicos y políticos; con expectativas (acceder a una parcela de tierra) acordes a sus posibilidades objetivas (campesinos pobres y sin tierras). Sus luchas durante este periodo aunque reivindicativas no cuestionaron las 
bases estructurales de la dominación, ${ }^{5}$ es decir, podían pensarse como campesinos propietarios de sus parcelas de tierra e independientes del patrón anterior (el terrateniente), milicianos del partido revolucionario (liderado por las élites pequeño burguesas), ciudadanos con derechos políticos para votar y elegir a los representantes de las élites económicas (aunque limitados y de acceso diferencial), pero lejos de sus expectativas estaba la posibilidad de pensarse como sujetos con capacidad de autogobernarse y gobernar en tanto práctica política institucionalizada. Ello explica por qué, a pesar de su protagonismo en el proceso revolucionario, no formaron parte del cogobierno que se instauró en los primeros años de la revolución nacionalista, conformado por la pequeńa burguesía articulada entonces al Movimiento Nacionalista Revolucionario (MNR) y a los sindicatos obreros bolivianos representados por la Central Obrera Boliviana (Zavaleta, 1986; Tapia, 2007). ${ }^{6}$

Es más, entre las bases campesinas e indígenas, por tal concordancia estructural, era poco factible que el "indio" fuera capaz de enseñar al propio "indio". Así lo cuenta Ramón Loayza, un dirigente sindical que fungía, al mismo tiempo, como promotor educativo de una organización no gubernamental en los años ochenta: "Nos decían: '¿Quiénes son estos viejitos? [... ] Aun así nos veían con abarcas, con sombrero y no nos escuchaba.' '¿Acaso vos sabes?', nos decían, 'como yo nomás eres'. O sea, el campesino se siente incapaz. Pero cuando comenzábamos a dar seminarios reaccionaban de otra forma: 'biencito habías sabido, ahora también yo quiero ser así” (Ramón, en Rasguido, 2006: p. 31).

Como efecto del vínculo político que creó el partido de la revolución nacionalista (el MNR), al dotar de tierras a los indígenas andinos, todavía a mediados de los noventa — recuerda un dirigente y profesionista de origen indígena— "la gente prefería votar por los partidos tradicionales como el MNR y el $\mathrm{MIR}^{7}[\ldots]$, cuando [veían] un indígena a la cabeza de un partido [decían] 'cómo ese nos va a gobernar es un t'ara (tonto o ignorante), yo tengo que apoyar a un partido más o menos [...], entonces no se daba cuenta que se estaba rechazando a sí mismo", pues consideraban que "apoyar a un indio igual a uno era desperdiciar

5 Distinto fue el levantamiento aymara liderado por Zárate Willka en 1899, lucha por la autodeterminación que llevó a los aymaras rebeldes a declarar la "República de indios" en Paria, Oruro (Condarco, 1982).

6 A pesar de que el cogobierno de 1952 permitió al sindicalismo obrero participar en la representación legislativa, en el poder legislativo, en el manejo de la economía, en la política macroeconómica, en la gestión de las minas nacionalizadas, en la dirección de las empresas económicas, dicho sector social también aceptó su condición de desigualdad y subordinación en el cogobierno, por su posición de clase subordinada del capitalismo y porque su participación política era, en cierta medida, ajena a su cultura o a su historia política interna (Tapia, 2007: pp. 13-14).

7 Movimiento de Izquierda Revolucionaria (MIR). 
su voto" ${ }^{8}$ Esta construcción imaginaria de sí, que proviene de la concordancia estructural, incidió en el poco éxito de los partidos políticos de origen indígena ${ }^{9}$ que, entre 1979 y 1997 , obtenían no más del $2.7 \%$ de la votación nacional (Toranzo, 2006: p. 448); mientras que para sobrevivir otros optaron por aliarse a partidos de izquierda o derecha. Este fue el caso del MRTKL que, a principios de los noventa, en alianza con el partido nacionalista de derecha (el MNR) llevó a su líder, Víctor Hugo Cárdenas, ${ }^{10}$ a la Vicepresidencia de la República.

Sin embargo, como apunta Bourdieu, la concordancia estructural no siempre se mantiene intacta sino que tiende a romperse. Siguiendo este argumento, Charlotte Nordmann sugiere que los principios prácticos en ciertos casos pueden engendrar "resistencias" y encontrarse en el origen de las impugnaciones a la dominación (Nordman, 2010). Ello es posible cuando esos principios ordenadores se contradicen con el orden presente de las cosas, cuando este ha cambiado desde la constitución del habitus de clase. Es decir, cuando los agentes individuales experimentan contradicciones entre sus expectativas subjetivas cambiantes (producto del habitus de clase relativamente modificado) y las oportunidades objetivas, cuya lentitud de movimiento parece inmovilizar a los agentes de sus posiciones sociales originarias. Tal contradicción abre una brecha en la reproducción social y da pie a un margen de libertad que permite un posible y probable cuestionamiento de las bases de la dominación social.

Así, el desfase estructural remite a la noción de cambio social que introduce Bourdieu en su marco analítico, ubicándolo en el espacio de reproducción del orden social: la escuela. Que el acceso a la escuela sea el ámbito que dará paso al desfase tiene que ver con el rol ambiguo que juega la escuela en la teoría bourdiana: "La escuela no sólo dispensa una enseñanza, ofreciéndole a cada cual los instrumentos técnicos para un dominio de su propia experiencia, sino que también [...] les da a todos la posibilidad de hacer la experiencia de la liberación con respecto a las urgencias prácticas, la única que permite el desarrollo de la 'disposición escolástica'” (Nordmann, 2010: p. 49).

Pero esta experiencia liberadora no es resultado mecánico del acceso al capital escolar, sino de una relación inversamente proporcional entre el acceso a la educación, cada vez más generalizado, y una cada vez mayor reducción de las

8 Entrevista a dirigente quechua del Sindicato de Campesinos del Departamento de Cochabamba, julio de 2006.

9 Me refiero al Movimiento Revolucionario Tupak Katari (MRTK), el Movimiento Revolucionario Tupak Katari de Liberación (мRткL), Movimiento Katarista de Liberación (мкL), además de otras vertientes políticas del mismo movimiento.

10 De origen aymara y pedagogo de formación, Víctor Hugo Cárdenas, fue fundador del MRTKL y cofundador de la Confederación Sindical de Trabajadores Campesinos de Bolivia (САтсв) a fines de los setenta. Antes, pero sobre todo después de su vicepresidencia, ha colaborado con organismos internacionales. 
posibilidades del mercado laboral en las sociedades contemporáneas (Bourdieu, 1999a). Dicha relación genera tensión y frustración entre los agentes individuales pues no consiguen la correspondencia entre sus títulos y las posiciones sociales que estos deberían facilitar. Ello, combinado con la inseguridad laboral, disuelve la coincidencia entre los habitus de los agentes y la realidad objetiva del mundo social fundamento de la dominación (Bourdieu, 1999a: p. 309; Nordmann, 2010: p. 53). ${ }^{11}$ Así, el desajuste al nivel del habitus, por un lado, y "la autonomía relativa del orden simbólico" que se potencia en estas situaciones de crisis, por otro, permiten cierta libertad a la acción política en el espacio de los posibles (Bourdieu, 1999a) introduciendo así un elemento clave para nuestro análisis: la reflexividad de los agentes sociales que experimentan el desajuste. ${ }^{12}$

\section{Ruptura estructural y la emergencia del intelectual indígena contemporáneo}

Aunque la sociedad boliviana es distinta a la que refiere Bourdieu (la francesa del 68), es clave admitir que un efecto perdurable de la Revolución Nacionalista de 1952 ha sido el acceso a la educación que ha tenido la población indígena boliviana desde los años sesenta (Salazar, 2012; Rea, 2011). Al mismo tiempo, acelerados procesos migratorios campo-ciudad derivaron en una mayor mercantilización de las economías campesinas (Albó, 2002), articuladas cada vez más a la economía capitalista (Untoja, 1989: p. 7). Por ello, aunque la educación posterior al proceso revolucionario no estuvo acompañada de una cualificación curricular ni infraestructural (Salazar, 2012), el acceso de las poblaciones indígenas a la educación, sobre todo de las ubicadas en las zonas andinas, fue generalizándose — mas no democratizándose — desde los años setenta. Los datos censales entre 1976 y 2001 muestran que en las zonas rurales andinas (principalmente) la tasa de analfabetismo se redujo de modo paulatino. Si a principios de los sesenta el área rural presentaba porcentajes altos de analfabetismo (mayor al 50\%), para 2001 había disminuido al 25\%, mientras que para 2005 los datos oficiales registran $8 \%$ de analfabetismo en Bolivia. Sin embargo, las cifras para los años de escolaridad no son tan alentadoras. El

11 Factor que también ayuda a comprender la ola de movimientos sociales — tras la crisis económica del 2008 - en países europeos y en Medio Oriente (los Indignados, la Primavera Árabe), en los que destacan los sectores profesionistas desempleados o en inseguridad laboral.

12 Aunque hablar de reflexividad parecería forzar la teoría de Bourdieu, este autor no rechaza tal concepto, solo que, a diferencia de los teóricos de la acción y las corrientes individualistas, no lo ubica como parte de un voluntarismo individual, sino como momentos de ruptura cuya durabilidad está dada por la adecuación en la práctica. 
promedio registrado para 2001 en el área rural era de 3.38 ańos de escolaridad, menor al dato urbano (7.9) y al promedio nacional (6.02). Por otra parte, para 2001, de la población boliviana de 25-59 años, el 65.2\% no había superado los nueve años de escolaridad ( $49.7 \%$ de $0-5$ años y $15.54 \%$ de $6-9$ años); mientras que el 20.4\% había alcanzado de diez a doce años y el 14.5\%, de trece a más años de escolaridad (INE, 2013; Ministerio de Educación 2004: p. 48). Este último (de trece a más años) es significativo si consideramos que, para el mismo periodo, la media latinoamericana alcanzó el $15.1 \%$, un poco mayor pero no distante del dato nacional que es superior al de Brasil (9.1\%) y al de Paraguay (11.1\%); muy similar al promedio que presenta México (14.4\%), pero por debajo de Argentina y Chile (Ministerio de Educación, 2004: p. 49).

A primera vista dichos datos no explican la masificación ni la generalización de la educación, como las que acontecieron en las sociedades europeas que refiere Bourdieu, y tampoco de ello se deduce qué porcentaje de la población de origen indígena accedió a más ańos de escolaridad, pues en el lapso que va de los sesenta al ańo 2000, el lugar de procedencia, el de residencia y la lengua materna, eran los indicadores de identidad étnica. Sin embargo, por el contexto social, tales indicadores eran poco confiables para dar cuenta de los cambios entre la población indígena en cuanto al acceso al capital escolar. Por ejemplo, si se toma el indicador de lugar de residencia para medir el grado de escolaridad, en un contexto donde la población indígena, sobre todo la joven, desde los setenta presenta altos índices de migración a los centros urbanos, el resultado es una población rural con muy baja escolaridad (3.38 en 2001), debido a que se conforma sobre todo de adultos mayores, olvidando que la población con más años de escolaridad de esas zonas rurales indígenas residían y residen en las zonas urbanas.

Asimismo, la lengua materna como criterio de identidad étnica era poco fiable —antes más que ahora—, pues en un contexto marcado por la discriminación racial, muchos de los migrantes rurales, sobre todos jóvenes, obviaban su lengua para evitar la discriminación (sin mucho éxito, ya que otros marcadores hacían visible su condición étnica). En cambio, el indicador de autoadscripción identitaria que se introdujo en el censo de 2001 mostraba proporciones más alentadoras respecto a la relación entre origen étnico y grados de escolaridad, pues del porcentaje de población mayor de 25 años con una escolaridad superior (normalistas, licenciados o técnicos superiores) el $51 \%$ se identificó con población de origen étnico, mientras que el restante afirmó no proceder de población indígena.

Estos datos permiten dos afirmaciones. Por un lado, durante la segunda mitad del siglo xx, sobre todo los indígenas de la parte occidental del país (aymaras y quechuas) accedieron a un importante capital escolar en una proporción cuantitativamente mayor, lo cual impactó en sus habitus de clase, en aquellas 
disposiciones de percepción que estructuran su propia praxis y, por tanto, su relación con el "otro" dominante. Así, relativamente dejaron de pensarse como sujetos subalternos, arraigados a la tierra como único modo de vida y sus expectativas de vida se ampliaron a ámbitos fuera de lo rural y de la condición de clase campesina y obrera, como se observa en la entrevista realizada a un aymara egresado de la carrera de filosofía a fines de los setenta:

Yo siempre quise estudiar, cuando tenía catorce años me escapí de mi casa y me fui a Oruro; trabajaba en el día y estudiaba en la noche, tenía buena cabeza. Después quería ser hermano, pero me junté y ya no pude entrar al seminario. Pero estudié filosofía en la Universidad Católica, con el apoyo de los hermanos Oblatos, pero no hice mi tesis, porque no me alcanzaba el dinero para mantener a mi familia y sacar la tesis, porque para ese entonces ya no me alcanzaba la beca. Me regresé a mi comunidad y he trabajado como promotor y maestro rural [...]. Por eso siempre quise que mis hijos estudiaran y les impulsé a estudiar siempre con vocación de servicio a la comunidad. Mis hijos son médicos, tengo una médico, tengo una odontóloga, una enfermera, un abogado, un ingeniero. Así les he impulsado a mis hijos (Mario M., Entrevista, 2014).

Sin embargo, los beneficios de estas inversiones personales y familiares (en términos afectivos y materiales) no necesariamente modificaron las condiciones materiales (cambios ocupacionales importantes) y simbólicas (estatus) que suponía el acceso a una formación superior, sobre todo por la rigidez de la estructura social boliviana. Tal rigidez se reproducía en un continuum mientras que el acceso al capital escolar no menguó —en muchos casos - el peso del prejuicio sobre una condición étnica. Es más, aunque la experiencia de relaciones sociales racializadas fue disminuyendo en intensidad no desapareció, se transformó en una práctica cada vez más sutil, al tiempo que más resistida, pero no por ello menos efectiva. Por ejemplo, algunos estudios sostienen que entre los sesenta y los noventa todavía se registraban peticiones ante los tribunales de justicia de cambio de apellidos de origen indígena por no indígenas (Loayza, 2004), pues en una sociedad racializada como la boliviana, el apellido constituía (y todavía constituye) un indicador importante sobre la procedencia étnica, cuyo sentido racializador tiende a ubicar a sus portadores en situación de riesgo a la discriminación racial. Este fue el caso, por ejemplo, de Víctor Hugo Cárdenas exvicepresidente boliviano, cuyo padre de apellido Choquehuanca solicitó el cambio de apellido a Cárdenas, esperando con ello menguar el peso del prejuicio que podían vivir sus hijos en la urbe.

Lo anterior repercutía materialmente, pues a pesar del acceso a la educación y de las expectativas que generó tal proceso — mayor movilidad social vía 
la conversión de los títulos en ingresos económicos-, los indígenas que accedían a un capital escolar difícilmente alcanzaban puestos laborales acordes a sus títulos, a posibilidades de ascenso en la jerarquía laboral y a remuneraciones equivalentes a su desempeño. En este sentido se puede observar que la mayoría de los individuos cuyas trayectorias de vida se resumen en los cuadros 1 y 2 , a pesar de años de trabajo en las mismas instituciones y de sus años escolares, difícilmente traspasaron su posición laboral de "promotores rurales" y, por ende, no alcanzaron remuneraciones según sus proyecciones; más aún, cuando laboraron bajo la figura de "servicio social", lo hicieron en espacios informales sin las prestaciones laborales establecidas por la ley. La excepción es el caso de un profesional aymara que, después de treinta años de servicio en distintas organizaciones no gubernamentales de carácter nacional e internacional, decidió formar su propia organización no gubernamental (ONG). Sin embargo, eso no le representó mayores ingresos e incluso, en una comparación con las percepciones mensuales de directores no indígenas de ONG, los de aquel equivalen a una tercera parte. Si bien no se puede argumentar que esa diferencia salarial se deba al origen étnico, sino a las redes sociales (nacionales e internacionales) que cada grupo sostiene, el reducido capital social en términos de redes nacionales e internacionales vinculadas a las esferas del poder sí limita a muchos profesionistas de origen indígena obtener mayores recursos materiales y sociales.

Cuadro 1. Intelectuales tradicionales. Trayectorias de vida

\begin{tabular}{|c|c|c|c|c|c|}
\hline \multirow[t]{2}{*}{ Variables } & \multicolumn{5}{|c|}{ Entrevistados } \\
\hline & Víctor S. & Mario O. & Juan C. & Petronila M. & Eliodoro C. \\
\hline $\begin{array}{l}\text { Año de } \\
\text { nacimiento }\end{array}$ & 1958 & 1928 & 1952 & 1939 & 1938 \\
\hline Procedencia & Poopó-Oruro & $\begin{array}{l}\text { Huayllamarca, } \\
\text { Oruro }\end{array}$ & Toledo, Oruro & Toledo, Oruro & $\begin{array}{l}\text { Huayllamarca, } \\
\text { Oruro }\end{array}$ \\
\hline $\begin{array}{l}\text { Ocupación } \\
\text { de los padres }\end{array}$ & $\begin{array}{l}\text { Agricultor, } \\
\text { propietario }\end{array}$ & $\begin{array}{l}\text { Agricultor, } \\
\text { propietario }\end{array}$ & $\begin{array}{l}\text { Madre pastora sin } \\
\text { tierras; padre arte- } \\
\text { sano residente }\end{array}$ & $\begin{array}{l}\text { Agricultor, pro- } \\
\text { pietario }\end{array}$ & $\begin{array}{l}\text { Agricultor, } \\
\text { propietario }\end{array}$ \\
\hline $\begin{array}{l}\text { Institución } \\
\text { educativa }\end{array}$ & $\begin{array}{l}\text { Pública rural/ } \\
\text { urbano }\end{array}$ & $\begin{array}{l}\text { Privada rural- } \\
\text { Pública urbana }\end{array}$ & $\begin{array}{l}\text { Pública rural- } \\
\text { urbana }\end{array}$ & $\begin{array}{l}\text { Privada rural- } \\
\text { Pública urbana }\end{array}$ & $\begin{array}{l}\text { Pública rural- } \\
\text { urbana }\end{array}$ \\
\hline $\begin{array}{l}\text { Vínculos pre- } \\
\text { vios a la vida } \\
\text { universitaria }\end{array}$ & Ninguna & $\begin{array}{l}\text { Iglesia católica, } \\
\text { Oblatos (Pro- } \\
\text { motor) }\end{array}$ & $\begin{array}{l}\text { Iglesia católica, } \\
\text { Oblatos (Cate- } \\
\text { quista) }\end{array}$ & $\begin{array}{l}\text { Iglesia católica, } \\
\text { Oblatos (Cate- } \\
\text { quista, promotora) }\end{array}$ & $\begin{array}{l}\text { Iglesia católica, } \\
\text { Oblatos (Pro- } \\
\text { motor) }\end{array}$ \\
\hline $\begin{array}{l}\text { Nivel de } \\
\text { escolaridad }\end{array}$ & Superior & Superior & Posgrado & Técnico & $\begin{array}{l}\text { Preparatoria } \\
\text { concluida }\end{array}$ \\
\hline Profesión & $\begin{array}{l}\text { Agrónomo, } \\
\text { Universidad } \\
\text { pública }\end{array}$ & $\begin{array}{l}\text { Maestro rural y } \\
\text { filósofo, Universi- } \\
\text { dad católica }\end{array}$ & $\begin{array}{l}\text { Mtro. en Enferme- } \\
\text { ría, Universidad } \\
\text { católica }\end{array}$ & $\begin{array}{l}\text { Auxiliar en En- } \\
\text { fermería, Centro } \\
\text { Oblatos }\end{array}$ & $\begin{array}{l}\text { Técnico agrope- } \\
\text { cuario, Centro } \\
\text { Oblatos }\end{array}$ \\
\hline $\begin{array}{l}\text { Trayectoria } \\
\text { laboral }\end{array}$ & $\begin{array}{l}\text { Técnico ONG } \\
\text { Iglesia católi- } \\
\text { ca-Oblatos }\end{array}$ & $\begin{array}{l}\text { Técnico ONG } \\
\text { Iglesia católica } \\
\text { Oblatos }\end{array}$ & $\begin{array}{l}\text { Técnico ONG, } \\
\text { director ONG }\end{array}$ & $\begin{array}{l}\text { Promotora de } \\
\text { salud }\end{array}$ & $\begin{array}{l}\text { Promotora de } \\
\text { salud }\end{array}$ \\
\hline $\begin{array}{l}\text { Trayectoria } \\
\text { político-sindical }\end{array}$ & $\begin{array}{l}\text { Alcalde } \\
\text { municipal }\end{array}$ & Ninguna & Ninguna & Ninguna & Ninguna \\
\hline
\end{tabular}

Fuente: Elaboración propia. 
Así, la mayor parte de los sujetos indígenas que invirtieron en un campo casi desconocido para ellos (la educación formal superior) y en el que depositaban altas expectativas de futuro (como romper con las barreras de la pobreza experimentada por sus padres, o las de la exclusión y la discriminación), comprobaron de diferente manera y en distintos momentos y grados la traducción reflexiva de la inconsistencia estructural. Estas experiencias diferenciales permiten comprender por qué un grupo muy reducido puede ampliar más que otros el margen de libertad que tienen los agentes para actuar en los márgenes de las condiciones de posibilidad que su posición social les permitía. ${ }^{13}$ Esto es, adquirir reflexividad que se tradujo en conciencia étnica, ${ }^{14}$ en una asunción política de la identidad (Bartolomé, 2006: p. 68). Ello no significa que antes del acceso a la educación formal los indígenas carecían de conciencia, sino que a la conciencia intuitiva que posee cualquier agente social — la cual resulta de la experiencia empírica interiorizada- se sumó una conciencia discursiva, representada por el "yo" que reflexiona (Bartolomé, 2006: p. 71).

En consecuencia, quienes asumieron esta conciencia étnica sobre su identidad no fueron todos los que experimentaron la inconsistencia entre el acceso a la educación y la persistencia de estructuras que los discriminaban, ni todos los que ya no se sentían cómodos en la función que el orden social les había asignado (Bourdieu, 1999a), sino quienes empezaron a cuestionar y asumir posturas políticas de reivindicación sobre sus identidades étnicas, cuando lo común era que las personas asumieran prácticas de desclasamiento, desindianización, asimilación o mimetismo cultural. ${ }^{15}$

Previo a su formación académica, la mayoría de nuestros entrevistados, aymaras o quechuas — que entre los años sesenta y setenta cursaron la educación media superior y superior-, accedieron en las zonas de origen a espacios institucionales distintos al académico: la Iglesia católica y ONG nacionales o internacionales. Estos espacios "reclutaban" a jóvenes indígenas (como informantes,

13 Este elemento de actuar en el margen de las condiciones de posibilidad que tienen los individuos y no fuera del margen de posibilidades lo retomo de Mendiola (2002).

14 Bartolomé define la conciencia étnica como "la manifestación ideológica del conjunto de las representaciones colectivas derivadas del sistema de relaciones interiores de un grupo étnico, las que se encuentran mediadas por la cultura compartida" (Bartolomé, 2006. Cursivas del autor).

15 La escuela había reforzado la correspondencia entre esperanzas subjetivas y oportunidades objetivas, al conseguir que los agentes indígenas comprendieran que la única posibilidad de inclusión en el Estadonación y la sociedad que los había excluido, marginado y discriminado cotidianamente, era sustituyendo sus identidades y prácticas culturales incluso a través de la autonegación y la mimetización cultural. Por ello muchos jóvenes indígenas que accedían (y acceden) a la educación superior asumían posturas de desclasamiento, reenclasamiento y prácticas de desindianización, pues estas constituían — de acuerdo a las políticas asimilacionistas de entonces - mecanismos adecuados para que los agentes se promovieran una movilidad social ascendente. 
catequistas, promotores o cuadros políticos, en todo caso, intermediarios), por cuyo medio se intentaba facilitar o hacer accesible la práctica ciudadana de las poblaciones indígenas o la evangelización de estas. Dichas instituciones fungieron como espacios de continuidad o de ruptura y reflexividad, ante la inconsistencia estructural que experimentaban.

Llama la atención el lazo estrecho de la mayoría de los entrevistados con la Iglesia católica. No obstante, los relacionados con la Congregación Oblata (cuadro 1) —que incursionó a Bolivia a fines de los años cincuenta para formar escuelas rurales de evangelización de la población indígena - no experimentaron "reflexivamente" el desfase estructural. Ello se puede observar si seguimos varios indicadores: 1) la mayoría de los que se vincularon desde temprana edad con la Congregación Oblatos (entre los sesenta y setenta) mantuvieron y mantienen esa relación desde su formación educativa básica en escuelas de la congregación hasta su paso por una universidad vinculada a la Iglesia católica, en ambos casos de carácter privado; 2) a pesar de su educación cualificada, no se modificó sustancialmente su posición laboral ni social, dado que pasaron de hijos de campesinos a "promotores sociales cualificados" en sus comunidades de origen (aunque residen en centros urbanos), lo que se ha mantenido a lo largo de sus trayectorias laborales (la mayoría desde mediados de los ochenta), en instituciones vinculadas a esa entidad religiosa; 3) tampoco se vincularon a la actividad política, exceptuando dos casos; a) Fernando U. que experimentó una desvinculación temprana de los hermanos oblatos, se vinculó al movimiento estudiantil en los setenta y tuvo una relación temprana y directa con la dinámica laboral y comercial del vecino Chile. ${ }^{16}$ b) En el caso de Víctor Q., el vínculo con la política y su función de alcalde de su municipio se asocian con un quiebre tardío (en términos de su trayectoria de vida) con la institución religiosa para la que trabajaba desde principios de los noventa, lo cual se observa en el fragmento de abajo, mismo que además permite comprender, sin ánimo de generalizar, cómo se establece la reflexividad sobre la inconsistencia estructural:

Estando dentro de la institución tuve la oportunidad de salir de Bolivia a Panamá con una beca por un mes, eso quizá ha sido para mí uno de los cambios porque más antes siempre consideraba que tener una fuente de trabajo era como para quedarse y si hacías bien te quedabas. Entonces tratabas de estimularte tú mismo pero al

16 Gran parte de la población aymara de donde procede Fernando U., por la cercanía con Chile, vivió una relación laboral estrecha y educativa con dicho país, lo que modificó su habitus, pues la mayor parte de los aymaras de esa región presentan una mayor cantidad de ańos de escolaridad respecto de otros aymaras del mismo departamento. De igual modo, como han incursionado en el comercio fronterizo, se ha modificado su situación económica en comparación con sus pares étnicos. 
final te dabas cuenta de que te estabas agotando más y no podías hacer nada porque había un temor que podías perder tu fuente de trabajo; entonces cuando salí de esa beca de trabajo a mi retorno ha cambiado, me ha gustado decir las cosas de frente, empecé a valorarme que no deben de pasarme esas cosas, ¿̨no?, y todo ese cambio para adelante un poco ya me metí con los cambios de participación en las reuniones de mi comunidad, ya teníamos conflictos al interior de la institución con la participación de la iglesia. Entonces yo un poco ya estaba queriendo entrar en ese movimiento en ese campo de la lucha y bueno tuve la oportunidad de estar de alcaldía [...], no hice carrera política pero sí una carrera social [...] manteniendo siempre la ideología (Víctor Q., Entrevista, 2014).

De lo anterior se deduce que los sujetos indígenas que conservaron el vínculo con la Iglesia católica (con la Congregación Oblatos) y que se mantienen activos para la misma, desempeñan todavía el papel de evangelizadores en calidad de "promotores sociales". En tal sentido, es posible afirmar que sabiéndose de origen indígena son intelectuales, pero no "intelectuales indígenas (orgánicos)" sino "tradicionales", pues sus discursos y conocimientos no contribuyen a la formulación de proyectos alternativos al discurso dominante nacional, basados en la valoración y legitimación de la diferencia y las particularidades étnicas. ${ }^{17}$ Recurren a elementos étnicos, pero los formulan para enriquecer un discurso evangelizador:

a la Universidad Católica fuimos diecisiete profesores rurales egresados [...] entonces ahí empezamos a estudiar, yo empecé a estudiar filosofía [...]. El compromiso era volver a Carangas, una vez en Carangas me he reincorporado al magisterio en mi pueblo en educación alternativa; entonces como ya conozco los aspectos teológicos, ya estaba empapado del aspecto religioso, de esa forma regresé; he dado algunas charlas como se esperó. Pero también yo como de la cultura me enfocaba un poco a lo que es la cultura, la iglesia nativa de aquí, eso no le gustó al obispo, no, entonces ya no puedo ser, antes era, mayormente era servir al sacerdocio a la iglesia pero yo no puedo servir si me olvido de mi cultura (Mario M., Entrevista, 2014).

Con lo señalado hasta acá, se sostiene la hipótesis de la no correspondencia entre el origen étnico, el acceso a capital escolar y el discurso de la etnicidad para designar a ciertos individuos étnicos bajo la categoría de "intelectuales indígenas" orgánicos; y que tal cuestión solo es posible cuando los sujetos lograron

17 Similar es el caso de los profesores normalistas de origen indígena en México que desde mediados de la década de los cuarenta fungieron como "intelectuales tradicionales" de los grupos gobernantes, impulsores de las políticas indigenistas de aquel entonces (Dietz, 1999). 
problematizar reflexivamente el desfase estructural y las entidades que reproducen tal situación. Este es el caso del segundo grupo de entrevistados, cuyas trayectorias se resumen en el cuadro 2. Este grupo también se vinculó tempranamente con entidades religiosas — sobre todo católicas y en particular con la congregación jesuita-, a través de ONG que hacían trabajo comunitario en las zonas de donde proceden los entrevistados. El lazo con la institucionalidad religiosa los proveyó de una red social que les permitió una educación formal de mejor calidad. Sin embargo, ese vínculo se fue rompiendo en distintos momentos, pero sobre todo, durante la etapa universitaria que, a diferencia del primer grupo, cursaron en instituciones públicas. Esto último no es tan relevante como el vínculo más directo con las actividades políticas, previas y posteriores a su formación universitaria.

Yo trabajaba en CIPCA, pero fui dado de baja en 1978 de cIPCA por haber fundado el мiтKA y opté porque no quise [ser] sirviente de los miristas; en esa época Hugo Fernández era director de la radio de CIPCA, que estaba ocupada por militantes del MIR y me sentenciaron a que no trabaje más en las radios, porque no estaba de acuerdo con el sistema y Jaime era tipificado como subversivo (Jaime A., Entrevista, 2008).

si ellos hubieran predicado la liberación de los pobres ahorita los pobres no hubiésemos estado así, por eso creo que la Iglesia es cómplice del sistema. [...] Hay sacerdotes que están con el pueblo pero son una minoría, porque los otros están con el sistema [...]. El sacerdote no solo debe hacer la misa, sino debe predicar también, debe ir a predicar como Cristo, y también los catequistas [...]. El catequista para mí es el que grita en el desierto; por eso, como he sido catequista ahora me sirve porque estoy gritando por todas partes el cambio del sistema de la injusticia de la mentira, del engaño. Si gritamos hartos, sería mejor. (Ramón, en Rasguido, 2008: pp. 40-41).

A lo anterior se añade que las regiones de donde procede la mayoría de los intelectuales indígenas que surgieron entre fines de los sesenta y los setenta, fueron exhaciendas fundadas entre fines del siglo XIX y principios del Xx, como parte de la expropiación de tierras comunales de aquel entonces (Irurozqui, 1999; Condarco, 1982). Por este factor histórico, desde la última parte de los treinta, los pobladores de esas regiones se relacionaron estrechamente con la práctica sindical, incluso antes de la influencia de las congregaciones católicas que llegan al terminar los cincuenta. En cambio, los intelectuales indígenas tradicionales proceden de zonas de tierras comunitarias, donde la población no experimentó una relación patronal. En estas la influencia sindical fue tardía, es más, hasta hoy las formas organizativas y las autoridades tradicionales, como el jilakata y el Mallku, son mucho más importantes que el sindicato, por lo que 
la forma de acción política también fue distinta. Esta relación diferencial respecto a la tenencia de la tierra y las formas organizativas tuvo un efecto en el cómo se experimentó la concordancia y el desfase estructural.

Es decir, hubo un efecto político del papel evangelizador de los jesuitas vinculados a la teología de la liberación y que trabajaban a través de las ONG, situación que no experimentaron los formados bajo la influencia oblata. La práctica política de las ONG que recurrían a estos indígenas como promotores para facilitar el proceso de "concientización" de las bases campesinas indígenas hizo visibles, incluso, las contradicciones internas de la propia Iglesia católica, o de las entidades con las que establecieron vínculos estrechos, en un contexto atravesado por la memoria reciente de las contradicciones de las relaciones patronales, que experimentaron unos y no otros. Todo esto explica los diferenciales con los que se experimentó la inconsistencia entre un habitus relativamente modificado por el acceso al capital escolar frente a la permanencia de las relaciones de dominación $\mathrm{y}$ de las posiciones sociales.

Cuadro 2. Intelectuales indígenas. Trayectorias de vida

\begin{tabular}{|c|c|c|c|c|c|c|}
\hline \multirow[t]{2}{*}{ Variable } & \multicolumn{6}{|c|}{ Entrevistados } \\
\hline & Felipe Q. & Alejo V. & Jaime A. & Ramón Loayza & Fernando U. Q. & Feliz P. \\
\hline Edad & 1942 & 1957 & 1937 & 1948 & 1950 & 1967 \\
\hline $\begin{array}{l}\text { Proceden- } \\
\text { cia }\end{array}$ & $\begin{array}{l}\text { Ayjalla, Omasu- } \\
\text { yos, La Paz }\end{array}$ & $\begin{array}{l}\text { Valle Central, } \\
\text { Cochabamba }\end{array}$ & $\begin{array}{l}\text { Ayllu Pasa, } \\
\text { Viscachani, } \\
\text { La Paz }\end{array}$ & $\begin{array}{l}\text { Pajcha, Inde- } \\
\text { pendencia, } \\
\text { Cochabamba }\end{array}$ & $\begin{array}{l}\text { Carangas, } \\
\text { Oruro }\end{array}$ & $\begin{array}{l}\text { Prov. Aroma, } \\
\text { La Paz }\end{array}$ \\
\hline $\begin{array}{l}\text { Ocupación } \\
\text { de los } \\
\text { padres }\end{array}$ & Agricultor & $\begin{array}{l}\text { Agricultor, } \\
\text { propietario }\end{array}$ & $\begin{array}{l}\text { Agricultor, } \\
\text { propietario }\end{array}$ & $\begin{array}{l}\text { Agricultor, } \\
\text { propietario }\end{array}$ & $\begin{array}{l}\text { Agricultor, } \\
\text { minero jornalero } \\
\text { Chile }\end{array}$ & $\begin{array}{l}\text { Agricultores, } \\
\text { comerciantes }\end{array}$ \\
\hline $\begin{array}{l}\text { Institución } \\
\text { educativa }\end{array}$ & Pública rural & $\begin{array}{l}\text { Pública rural- } \\
\text { urbana }\end{array}$ & $\begin{array}{l}\text { Pública } \\
\text { rural-urbana }\end{array}$ & $\begin{array}{l}\text { Pública rural } \\
\text {-Urbana }\end{array}$ & $\begin{array}{l}\text { Privado rural- } \\
\text { Público urbana }\end{array}$ & Pública \\
\hline $\begin{array}{l}\text { Vínculos } \\
\text { previos a la } \\
\text { vida univer- } \\
\text { sitaria }\end{array}$ & ----- & $\begin{array}{l}\text { ONG, } \\
\text { vinculada a } \\
\text { los católicos } \\
\text { jesuitas }\end{array}$ & $\begin{array}{l}\text { Iglesia adven- } \\
\text { tista }\end{array}$ & $\begin{array}{l}\text { ONG, Iglesia } \\
\text { católica } \\
\text { (jesuitas) } \\
\text { catequista/ } \\
\text { promotor }\end{array}$ & $\begin{array}{l}\text { Iglesia católica, } \\
\text { Oblatos. }\end{array}$ & ----- \\
\hline $\begin{array}{l}\text { Nivel } \\
\text { escolaridad }\end{array}$ & Superior & Superior & Técnico & $\begin{array}{l}\text { Preparatoria } \\
\text { inconclusa }\end{array}$ & Posgrado & Posgrado \\
\hline Profesión & Historiador & $\begin{array}{l}\text { Ciencias de } \\
\text { la Educación }\end{array}$ & Normalista & Técnico & $\begin{array}{l}\text { Dr. economista } \\
\text { y filósofo }\end{array}$ & Dr. sociólogo \\
\hline $\begin{array}{l}\text { Trayectoria } \\
\text { laboral }\end{array}$ & $\begin{array}{l}\text { Dirigente } \\
\text { sindical }\end{array}$ & $\begin{array}{l}\text { Promotor } \\
\text { ONG (influen- } \\
\text { cia jesuita), } \\
\text { agricultor }\end{array}$ & $\begin{array}{l}\text { Maestro rural, } \\
\text { promotor en la } \\
\text { ONG (influen- } \\
\text { cia jesuitas) }\end{array}$ & $\begin{array}{l}\text { Promotor so- } \\
\text { cial en ONG, } \\
\text { (influencia } \\
\text { jesuitas, Hnas. } \\
\text { Jesús María) }\end{array}$ & $\begin{array}{l}\text { Docente } \\
\text { universitario, } \\
\text { Investigador del } \\
\text { CADA, CICON }\end{array}$ & $\begin{array}{l}\text { Docente } \\
\text { universitario }\end{array}$ \\
\hline $\begin{array}{l}\text { Trayectoria } \\
\text { político- } \\
\text { sindical }\end{array}$ & $\begin{array}{l}\text { Dirigente } \\
\text { CSUCB, Funda- } \\
\text { dor de MITK, los } \\
\text { Ayllus Rojos y } \\
\text { del EGTK, fun- } \\
\text { dador del MIP }\end{array}$ & $\begin{array}{l}\text { Dirigente } \\
\text { sindical } \\
\text { de bases, } \\
\text { dirigente } \\
\text { FSUTCC, } \\
\text { CSUTCB }\end{array}$ & $\begin{array}{l}\text { Dirigente } \\
\text { sindical de ba- } \\
\text { ses, miembro } \\
\text { del MITKA, } \\
\text { dirigente del } \\
\text { magisterio, } \\
\text { Apu Mallyu }\end{array}$ & $\begin{array}{l}\text { Dirigente } \\
\text { sindical } \\
\text { departamental, } \\
\text { fundador del } \\
\text { IPSP, diputado } \\
\text { nal. constitu- } \\
\text { yente }\end{array}$ & $\begin{array}{l}\text { Fundador MKN } \\
\text { Movimiento Ka- } \\
\text { tarista Nacional, } \\
\text { Diputado, }\end{array}$ & $\begin{array}{l}\text { Dirigente } \\
\text { Sindical, Ex } \\
\text { militante MAS, } \\
\text { Ex. Ministro } \\
\text { de gobierno }\end{array}$ \\
\hline
\end{tabular}

Fuente: Elaboración propia. 
Por lo tanto, el tránsito por esas instancias proveyó a este segundo grupo de los elementos (conocimientos/información) necesarios para cuestionar el orden social dominante; ya sea porque esas instancias se asumían como "portadoras de la reflexividad" mediante los procesos de formación de "promotores sociales", cuya labor era educar a las bases a través de eventos de capacitación informal; o porque fue en esos espacios donde los jóvenes indígenas empezaron a advertir el desfase estructural debido a la adquisición de capitales sociales, económicos y escolares acompañados de nuevas expectativas que se convirtieron en imposibilidades en tanto no modificaban su posición social: su condición de sujetos pobres, subordinados y dominados. Podrían llegar a ser intermediarios o promotores sociales, mas no técnicos ni profesionistas; catequistas o diáconos, pero no sacerdotes. ${ }^{18}$ "La masa campesina" aliada estratégica del "sujeto histórico" (del proletariado boliviano), mas no "él sujeto histórico". Ello hizo más reflexivo a este grupo sobre el orden de la dominación no solo clasista sino también étnico-cultural.

A tal hecho apunta la ruptura de Felipe Quispe con sus aliados de la izquierda marxista. Aunque sus vínculos tempranos con la dirigencia sindical y sus lecturas de Fausto Reinaga marcaron su trayectoria —inclinada a un activismo político radical del movimiento katarista—, la reflexividad sobre la inconsistencia estructural tuvo un segundo momento en su relación con el liderazgo de los jóvenes no indígenas marxistas compañeros de guerrilla. Según las declaraciones de Quispe, la ruptura política con la fracción no indígena del grupo guerrillero "Ayllus Rojos", del cual García Linera era miembro, se dio por las contradicciones ideológicas que reproducían la dominación social, pues los indígenas guerrilleros estaban subordinados al liderazgo político e ideológico de los guerrilleros no indígenas. Esta contradicción, reflexiona Quispe, les permitió pensar que la lucha indígena por la autonomía política implicaba romper "con sus anteriores amos" fueran de izquierda o derecha, pues ambos eran "q'aras" (Entrevista, Felipe Quispe, 2003, 2006). Similar reflexión se puede encontrar en los escritos de Fernando Untoja, quien destaca la relevancia de la autonomía ideológica katarista frente a ideólogos de izquierda (Untoja, 1991).

En este contexto surgieron los intelectuales orgánicos indígenas que, nutridos de la influencia política de ciertos sectores de la Iglesia católica, de las redes que articularon con o sin ella, ${ }^{19}$ de los conocimientos académicos adquiridos en

18 Un estudio sobre los diáconos indígenas en Chiapas, México, muestra esta reproducción del orden en la Iglesia católica, incluso en las fracciones inclinadas a la teología de la liberación. Véase Mosqueda (2013).

Cabe aclarar que el desfase estructural no es específico de las últimas cuatro décadas señaladas, ni se genera por la correlación entre masificación de la educación y estrechez del mercado laboral, aunque lo primero sea relevante. Por ejemplo, el movimiento de los caciques apoderados de principios del siglo xx, en el que el acceso a la escuela básica —el dominio de la lectoescritura del español— contribuyó al desfase y a la "conciencia discursiva”, lo que permitió su disputa legal por el reconocimiento de los tí- 
centros de formación universitaria, de los debates con y contra los intelectuales marxistas, entre fines de los sesenta y a lo largo de los setenta, dieron forma al katarismo, un movimiento político, ideológico y cultural que reivindicó las luchas indígenas coloniales — en particular la de Tupak Katari de 1789_- para proveer al campesino-indígena un discurso distinto al nacionalismo de sus aliadas élites pequeño burguesas no indígenas; pero también distinto al discurso clasista de los intelectuales de izquierda ${ }^{20}$ a pesar de las diferencias internas.

Ahora bien, las generaciones siguientes y el rumbo que tomó el movimiento indígena también fueron resultado de las experiencias individuales o colectivas, pues sus esperanzas subjetivas proyectadas por el acceso a una educación superior se truncaron por el persistente racismo en el mundo urbano - una de las formas simbólicas de la rigidez en la estructura de la movilidad social—, y porque se vieron expuestos a mayor inseguridad laboral, abaratamiento de la mano de obra manual y no manual, y desempleo e informalidad originados en las reformas estructurales neoliberales; todo esto afectó a gran parte de la población boliviana, pero más a los profesionistas. ${ }^{21}$ Sin embargo, mientras había quien contaba con capitales más allá del escolar (el cultural, el social, el simbólico, el racial ${ }^{22}$ ) para amortiguar el impacto de las crisis económicas sobre sus posiciones sociales, la mayoría de los indígenas, incluidos los que habían adquirido títulos escolares, fue desplazada a la informalidad, agudizando y evidenciando la inconsistencia estructural. Así, mientras la población indígena sin títulos escolares fue desplazada al mercado informal (INE, 2002), muchos profesionistas indígenas se desprofesionalizaron trabajando de taxistas o comerciantes, o combinando estas actividades con el ejercicio también informal de su profesión, en el mejor de los casos, ocupando cargos municipales o en ONG que no ofrecían prestaciones laborales al quehacer profesional, pero sí un contenido político. ${ }^{23}$

tulos de propiedad que les había otorgado la Corona Espańola durante la colonia (Rivera, 1986). Igual función tuvo la experiencia de Warisata, la "Escuela Ayllu", un proyecto educacional "desde abajo" que pretendía reforzar los patrones culturales aymara convirtiendo la escuela en un centro de organización comunitaria.

20 Es el caso del aymara Fausto Reinaga, que desde los sesenta y por su ingreso a los espacios de formación académica se aproximó y distanció del marxismo; mientras que su acercamiento a los debates de intelectuales como Franz Fanon le permitió introducir en la discusión del movimiento campesino, el problema del coloniaje y su posterior desplazamiento del marxismo a la perspectiva indigenista (Portugal, 2013).

21 En la década de 1980, la población ocupada en la informalidad alcanzó el 30\%; para 2001, esta cifra creció hasta el $60 \%$. Los más afectados fueron los de origen indígena.

22 En otro estudio he argumentado acerca de la importancia de la categoría racial como capital particular, en el sentido postulado por Bourdieu: constituye un recurso en disputa en diferentes campos sociales.

Datos de entrevistas obtenidas entre 2006, 2008 y 2012. 
A esa generación pertenece la mayoría de los aymaras académicos que Salazar (2012) describe como intelectuales indígenas, los cuales, a diferencia de los "intelectuales indígenas orgánicos" y de los "intelectuales tradicionales", presentan discursos políticos nutridos y legitimados en una producción e institucionalidad académicas, posicionándose más como académicos que como intelectuales, pues esto último en tanto función y los vínculos con las bases sociales indígenas de procedencia son más remotas y alejadas que su quehacer académico-intelectual. En este segmento, la tensión entre ser un "científico" y a la vez un intelectual es más problemático, dado que la intención de constituirse como intelectuales (indígenas) esta cooptada por la de ser académicos, ya que no están liberados del todo de las exigencias que impone la especialización técnica; y como se encuentran relativamente coercionados por la institución donde se desempeñan (centros de investigación, universidades), hallan límites a su emisión de juicios de valor generales e intransigentes (Berger, en Bourdieu, 2006). Una situación distinta viven los "intelectuales orgánicos" cuya labor intelectual y política puso en segundo plano su actividad académica "científica"; esos son los casos de Felipe Quispe, de Alejo Veliz, o de aquellos que lograron un equilibro inestable en estos dos campos de acción, como Víctor Hugo Cárdenas y Fernando Untoja.

Sin embargo, ha existido una relación recíproca entre los intelectuales "orgánicos" y los "académicos", pues ambos se legitiman mutuamente y lo mismo hacen con sus posiciones en los campos de acción donde intervienen. Es decir, pese a su formación académica, los intelectuales indígenas orgánicos requirieron del discurso académico para legitimar sus discursos políticos (aunque también producían sus propios conocimientos: Quispe tiene escritos históricos, Untoja es columnista en la prensa escrita). Mientras que los académicos han requerido de los orgánicos para verificar sus supuestos de trabajo, al grado de legitimarse ante la opinión pública y la académica nacional como especialistas de la acción colectiva indígena (pasada o presente).

\section{La reconfiguración del campo intelectual boliviano}

Fue necesaria esta revisión del desfase estructural tanto para explicar la especificidad del indígena como intelectual y del intelectual como indígena, como para comprender el papel de los intelectuales indígenas en el ciclo de protestas en Bolivia registrado entre 1999 y 2005. Unos como parte del movimiento actuando como dirigencia y otros como "intérpretes del movimiento". En los dos casos, los discursos políticos y académicos generados proveyeron de este tipo de dispositivos al movimiento. Los intelectuales indígenas, en tanto filó- 
sofos, antropólogos, historiadores y sociólogos (apoyados por investigadores e intelectuales no indígenas y centros de investigación como el Taller de Historia Oral Andina (тноА), el Centro de Investigación y Promoción del Campesinado (CIPCA) y el Centro de Comunicación y Desarrollo Andino (CENDA), entre otros), contribuyeron a la reconstrucción de la historia de los movimientos indígenas anteriores a 1952 (al proceso nacionalista revolucionario), a la reconstrucción de la cosmovisión indígena andina (fundamentalmente) pensada como filosofía, a la recuperación de las lenguas aymara y quechua, a la realización de estudios de la economía y la reciprocidad andina, así como en los estudios sobre las formas de organización política en torno al ayllu (como unidad territorial), dotando de elementos simbólico-identitarios y de contenido al discurso étnico-cultural del movimiento indígena. Estos mismos insumos sirvieron para la lucha en un campo distinto al de la acción política: el intelectual, donde el recurso en disputa era y es la legitimidad de su práctica intelectual y la "objetiva" interpretación de la realidad: el sentido de la acción del movimiento indígena.

De lo anterior se puede sostener que durante el ciclo de protestas indígenas de principios del 2000, se reconfiguraron los campos político e intelectual de Bolivia. Hasta la década de los noventa, este último — sobre todo las ciencias sociales - estaba dominado por intelectuales no indígenas con inclinaciones políticas de derecha o izquierda. Unos apelando a su "neutralidad científica" y otros reafirmando su activismo político en calidad de intelectuales orgánicos; en uno y otro caso el rasgo específico fue su condición de clase: medias altas y bajas predominantemente no indígenas. Unos se asumían como parte del grupo dominante (dominantes-dominados), en especial los que defendían que su práctica intelectual era "objetiva y neutra"; los otros se articulaban con las clases dominadas y, por tanto, correspondían al segmento social dominados-dominantes.

El escenario en el campo intelectual descrito fue cambiando desde los noventa, no solo a raíz de la relativa masificación de la educación y el acceso a los espacios educativos que tenía la juventud rural de procedencia indígena, sino porque los académicos indígenas lograron posicionarse en dicho campo legitimando para sí el discurso de la etnicidad (aunque no de modo exclusivo ni excluyente) favorecido, además, por el contexto internacional. Por sus trayectorias de formación académica y residencia urbana, muchos de ellos perdieron vínculos con su lugar de origen sin embargo, ello no necesariamente supuso la pérdida de su etnización (conciencia discursiva), la cual se reforzaba y se refuerza, por su posición política y práctica intelectual desarrollada, la mayoría de las veces, en las instituciones donde laboran (ong con trabajo en las áreas rurales); o a partir de sus nexos con organizaciones sociales que 
dirigían o atendían en tanto dirigentes sociales o asesores de estos. Todo ello les ha permitido iniciar un "retorno" a sus orígenes, en términos tanto materiales como simbólicos.

Ahora bien, este reposicionamiento en el campo intelectual se dio en el contexto de disputa por la "adecuada" interpretación del sentido de la acción del movimiento que implicaba distintas concepciones de la sociedad boliviana y de proyectos de nación. Unos, los académicos no indígenas del segmento dominados-dominantes, asociaban la emergencia de los movimientos indígenas a los efectos de las reformas estructurales neoliberales impuestas a mediados de los ochenta, por ejemplo, la ampliación de la desigualdad en detrimento de las economías campesinas, imposibilitadas así de participar en un mercado desregulado. ${ }^{24}$ Esto daba paso a las contradicciones de clase, y a partir de esta identificaron al movimiento indio como expresión del "fracaso" y la "derrota neoliberal". De este modo encontraron en el "re-surgimiento" de los movimientos indígenas al sujeto portador del sentimiento antineoliberal y contestatario que podía remplazar al histórico movimiento minero de estatismo nacional.

Por su parte, algunos académicos indígenas, en tanto intelectuales, sin rechazar la lectura materialista del crecimiento de las desigualdades, afirmaban que el fondo del conflicto eran todavía las contradicciones étnico-raciales. La persistencia de lo colonial, por lo tanto, era una de las causas del ciclo de protestas 1999-2005:

Hay relaciones de discriminación étnica que son muy fuertes, vistas incluso como naturales. Esto se nota en la vida cotidiana [...] cuando las señoras o caballeros 'distinguidos' usan perfumes desodorantes para tratar de hacer desaparecer el olor y posiblemente el color del resto de los pasajeros. Hay una construcción social y cultural de fronteras étnicas que se manifiestan como habitus [...] y una construcción racial de las relaciones sociales entre los indígenas y los sectores blanco-mestizos que de tiempo en tiempo se manifiestan en violencia simbólica y física. La masacre estatal-gubernamental de la ciudad de El Alto el 12 de octubre de 2003 [...] es un acto político militar de estas construcciones racistas del poder en Bolivia (Mamani, 2004: p. 25).

En cambio los intelectuales del segmento dominantes-dominados ${ }^{25}$ reconocían la discriminación étnica, pero difícilmente afirmaban que existiera racismo en Bolivia. Consideraban que este era una retórica política de los intelectuales

24 García (2001, 2003, 2005), Prada (2004), Tapia (2002, 2007) y Tapia \& Gutiérrez et al. (2000).

25 Véanse Mansilla (2003, 2004), Laserna (2003a, 2003b), Lazarte (2003, 2005). 
de izquierda, de los activistas y de los movimientos sociales. Argüían que si tal fenómeno existía, y las desigualdades económicas coincidían con las diferencias étnicas, eran consecuencias del pasado y de las prácticas conservadoras y tradicionales de los sectores populares (Mansilla, 2003). Incluso algunos enfatizaban el carácter mestizo de la población apelando a la inevitabilidad del mestizaje de la condición humana, para señalar que si existían poblaciones indígenas en Bolivia eran minoritarias. De esta forma el tema de las mayorías indígenas resultaba ser parte de una falacia interpretativa del dato censal, pues no incorporaba opciones como el mestizaje (Toranzo, 2009).

En este campo intelectual de disputa es difícil hablar de ganadores o perdedores, pero sí es válido argumentar que las interpretaciones de algunos académicos de origen indígena dotaron al movimiento indígena de argumentos para que estos se nombraran y reconocieran como "moralmente iguales" ante aquellos que se atribuían el poder de nombrar, clasificar y reconocer. Tal argumento sostenían los discursos del movimiento, sobre todo los de la fracción liderada por Felipe Quispe quien denunciaba la presencia de una Bolivia partida en dos: "la de los indios y la de los q'aras".

Este discurso de igualación y de ruptura, nutrido por las interpretaciones de los intelectuales y académicos indígenas, argumentó como legítimo el derecho a la palabra y a cuestionar la inconsistencia del orden social. Solo desde este proceso es posible afirmar que los indígenas, en su condición de movimiento, disputasen la conducción del país por medio de la práctica política institucionalizada.

Cabe aclarar que este reposicionamiento de los indígenas en el campo intelectual solo fue posible tras reducir su práctica intelectual al mundo de lo académico, de la escritura y de los "títulos escolares", además de reconocer dicha práctica como la forma hegemónica de generar conocimiento, desde la cual se han producido los discursos étnicos que han sustentado al movimiento indígena, desplazando a un segundo plano las prácticas intelectuales que no caben en el academicismo (Mato, 2002).

Es decir, la reivindicación de lo étnico y de los saberes ancestrales, y la producción del discurso de la descolonización se realizan principalmente desde la misma tecnología de poder/saber hegemónico que se cuestiona y critica, desde el discurso de la etnicidad. No porque se experimente un "falso discurso indígena" o un uso racional instrumental de la identidad étnica (como lo piensan algunos intelectuales del segmento dominantes-dominados), sino que los indígenas, como los intelectuales indígenas, fueron atravesados y son producto de todo el movimiento cultural homogeneizante que se produjo durante la segunda mitad del siglo xx. Ello no quiere decir que se requiere un retorno a lo "verdaderamente indígena" (que no existe como condición ontológica), sino que la fuerza del discurso de la etnicidad y el aporte de los intelectuales indígenas 
se concreta en la traducción, reinterpretación y reinvención de lo indígena contemporáneo y en el cómo estas traducciones dotan de instrumentos de negociación, transgresión y reposicionamiento en los diferentes campos de acción, del político al intelectual, del intelectual al político y de estos al económico. No olvidemos que en el campo económico, Bolivia, sobre todo en su parte occidental, experimenta una relativa reconfiguración con la presencia cada vez más explícita y más contundente de una élite económica comercial de origen indígena que, apelando a su etnicidad (recuperada del discurso del movimiento indígena) y a sus prácticas culturales traducidas, traducen y se mueven en un mercado altamente competitivo, capitalista y global.

\section{Conclusiones}

Para comprender los cambios sociopolíticos y económicos que Bolivia experimenta desde principios del siglo XXI, es importante virar el análisis hacia el origen y el papel de los intelectuales en los treinta años previos al último ciclo de protestas, lo cual resulta de las aperturas que se generaron en términos estructurales: que una cada vez mayor masa de población indígena haya accesado a la educación, y los desajustes que esto provocó en el orden de la reproducción social, como: a) la apertura de otros espacios sociales estructurales y estructurantes (la escuela) que generaron desajustes entre el habitus de clase -relativamente modificado por el efecto de la escuela — y la escasa movilidad de las posiciones sociales de los sujetos sociales, y $b$ ) la apertura de espacios de participación política local, que permitieron la fisura del orden. Pues, mientras estos espacios reducidos se abrían de forma relativa, más evidentes eran las barreras y brechas de la diferenciación social, entre los que se clasificaban y reconocían como indígenas y quienes dominaban los instrumentos del poder político y económico, y mantenían el control de la nominación y clasificación de la población, de sus prácticas y de sus representaciones.

Este proceso motivó la "reflexividad" entre los sujetos atados a las estructuras, lo que introdujo la posibilidad de elección, de autonomía social y de cuestionamiento del orden de dominación. En este proceso se ubica la constitución de los intelectuales indígenas en tanto intelectuales orgánicos; es decir, el vínculo histórico, mas no natural, entre el rol social (intelectual), el origen étnico, el acceso al capital escolar y la apropiación del discurso de la etnicidad.

A partir de tal proceso se comprende la contribución de los dispositivos políticos y académicos en la reinvención del movimiento indígena boliviano contemporáneo en sus sentidos políticos y culturales. Culturales porque el debate con los marxistas y su aproximación a intelectuales como Franz Fanon, a 
intelectuales bolivianos de origen indígena como Fausto Reinaga, y a la propia historia del movimiento indígena boliviano, permitieron que ese movimiento reivindicara la diversidad cultural, étnica y racial por sobre la reivindicación de clase (Toranzo, 2006: p. 447). La reinvención política deviene de esta discusión cultural entre intelectuales y académicos indígenas al interior del movimiento indígena, tras la ruptura del pacto militar campesino luego de la masacre campesina en 1974; la reflexividad sobre la no correspondencia entre las expectativas subjetivas y las posibilidades objetivas que empezaron a reflejarse en el voto de las bases indígenas por su igual étnico y el acceso de profesionistas y dirigentes indígenas al control de espacios político-administrativo a nivel municipal, desde los noventa; y es en el siglo XXI cuando las bases indígenas lograron autorrepresentarse eligiendo a sus iguales como representantes políticos no solo locales sino nacionales (Toranzo, 2006: p. 449).

Esta autorreafirmación que se dio mediante la autorrepresentación y que se nutrió del discurso de los intelectuales indígenas, no es más que el resultado del cuestionamiento a las estructuras del orden de la dominación. Sin embargo, como argumenta Bourdieu, mientras este margen de libertad como base de la autonomía de las luchas sociales abre el porvenir, las ortodoxias, por ser discursos que mantienen el orden simbólico, tratan de cerrar de nuevo el abanico de las posibilidades para intentar hacer creer que ya todo está decidido, mediante un aserto performativo disfrazado de verdad absoluta (Bourdieu, 1999a: p. 311). En esta línea argumentativa apunta una parte de los intelectuales indígenas crítica del gobierno de Morales, respecto a la direccionalidad política y económica que va tomando el proceso de cambio que experimenta la Bolivia del siglo xxI.

\section{Referencias}

Albó, X. (2002). Los indígenas en la política. La Paz: CIPCA.

Bartolomé, M. A. (2006). Los laberintos de la identidad. En Procesos interculturales. Antropología política del pluralismo cultural en América Latina (pp. 63-84). México: Siglo XXI.

Bourdieu, P. (1999a). Meditaciones pascalinas. Barcelona: Anagrama.

Bourdieu, P. (1999b). Intelectuales, política y poder. Buenos Aires: Eudeba.

Bourdieu, P., Passeron, J. C. \& Chamboredon, J. C. (2008 [1975]). El oficio de sociólogo. Presupuestos epistemológicos. México: Siglo XXI. 
Condarco, R. (1982 [1965]). Zárate el "temible” Willka. Historia de la rebelión indígena de 1899 en la República de Bolivia, seg. edición revisada. La Paz: Renovación LTDA.

Dietz, G. (1999). La comunidad purhépecha es nuestra fuerza. Etnicidad, cultura y región en un movimiento indígena en Michoacán. Quito: Ediciones Abya-Yala.

García, Á. (2005). La lucha por el poder en Bolivia. En Horizontes y límites del Estado y el poder. La Paz: Muela del Diablo.

García, Á. (2003, junio). La crisis del Estado. Tinkazos. Revista Boliviana de Ciencias Sociales, (14). Recuperado de http://www.scielo.org.bo/scielo.php?script=sci_arttext\&pid=S1990 $-74512010000300002 \& \operatorname{lng}=$ es\&nrm=iso $>$.

García, Á. (2001). Sindicato, multitud y comunidad. Movimientos sociales y formas de autonomía política en Bolivia. En Tiempos de Rebelión. La Paz: Muela del Diablo.

Gramsci, A. (1977). La formación de los intelectuales. México: Grijalbo.

Instituto Nacional de Estadística (2002). Censo Nacional de Población y Vivienda 2001. Bolivia. La Paz: INE, CD-ROM.

Irurozqui, M. (1999). Las paradojas de la tributación. Ciudadanía y política estatal indígena en Bolivia, 1825-1900. Revista de Indias, Estado y politica indígena, Hispanoamérica, Estados Unidos y Australia, S. XVI-XX, LIX(217), 705-740.

Laserna, R. (2004). La democracia en el ch'enko. La Paz: Fundación Milenio.

Laserna, R. (2003a). Bolivia: entre el populismo y la democracia. Nueva Sociedad, (188), 4-14.

Laserna, R. (2003b). Bolivia: la crisis de Octubre y el fracaso del Ch'enko. La Paz: CERES.

Lazarte, J. (2008). Derrumbe de la "res-publica". Los procesos electorales en Bolivia: 2002, 2004, 2005. La Paz: Plural.

Lazarte, J. (2005). Entre los espectros del pasado y las incertidumbres del futuro. Politica y democracia en Bolivia a principios del siglo XXI. La Paz: Plural.

Lazarte, J. (2003). El conflicto entre un estado del 'demos' y un estado del 'etnos'. Apuntes para un Debate. Tinkazos. Revista Boliviana de Ciencias Sociales, 6(14), 51-78.

Loayza, R. (2004). Halajtayata. Etnicidad y Racismo en Bolivia. La Paz: Garza Azul. 
Mamani Ramírez, P. (2003). El rugir de las multitudes. La fuerza de los levantamientos indígenas. La Paz: Muela del Diablo.

Mansilla, H. C. F. (2003). Identidades colectivas y fundamentalismo indigenista en la era del pluralismo evolutivo boliviano. Ecuador Debate, (48).

Mato, D. (2002). Estudios y otras prácticas intelectuales latinoamericanas en cultura y poder. Mato, D. (Coord.). Estudios y otras prácticas intelectuales en cultura y poder (pp. 21-46). Caracas: CLACSO/CEAP/FACES/Universidad Central de Venezuela.

Mendiola, I. (2002). Los movimientos sociales y trayectos sociológicos. Hacia una teoría práxica y multidimensional de lo social. País Vasco: Universidad del País Vasco.

Ministerio de Educación. (2004). La educación en Bolivia. Indicadores, cifras y resultados. La Paz: Ministerio de Educación.

Mosqueda Tapia, E. (2013). La Iglesia autóctona y las desigualdades sociales en la diócesis de San Cristóbal de Las Casas, 1975-2007. En Judd, E. \& Mallimaci, F. (Coords.), Cristianismos en América Latina: Tiempo presente, historias y memorias (pp. 61-91). Buenos Aires: CLACSO-CROP.

Nordmann, Ch. (2010). Bourdieu/Rancière. La politica entre sociología y filosofía. Buenos Aires: Nueva Visión.

Prada, R. (2004). Largo octubre. Genealogía de los movimientos sociales. La Paz: Plural.

Prada, R. (2001). La fuerza del acontecimiento. Tiempos de rebelión. La Paz: Muela del Diablo.

Portugal Mollinedo, P. (2013, junio). La etapa marxista del pensamiento de Fausto Reinaga. Pukara. Cultura, Sociedad y Politica de los Pueblos Originarios, 7(82), 6-8.

Rappaport, J. (2007, julio-septiembre). Intelectuales públicos indígenas en América Latina: Una aproximación comparada. Revista Iberoamericana, LXXIII(220), 615-630.

Rea Campos, C. (2006). “Porque no quiero que mi hija sea tu sirvienta...!”. Movimientos indios y conflictividad social en Bolivia en los albores del siglo XXI. Tesis de maestría. Flacso México.

Reinaga, F. (1969). La revolución india. La Paz: Partido Indio de Bolivia.

Rasguido, S. (2006). Ramón Loayza Caero: Lider quechua, contribuyó al ascenso campesino indígena del país. La Paz: cipCA. 
Rivera, S. (1986). Oprimidos pero no vencidos. Luchas del campesinado aymara y quechua de Bolivia, 1900-1980. Ginebra: UNRISD.

Salazar, C., Mirko Rodríguez, J. \& Evi Sulcata, A. (2012). Intelectuales aymaras y nuevas mayorías mestizas. Una perspectiva post 1952. La Paz: Fundación PIEB.

Tapia, L. (2007). La igualdad es cogobierno. La Paz: Plural/cides/Umsa/ASDI-ASAREC.

Tapia, L., Gutiérrez, R. \& García, Á. (2000). El retorno de la Bolivia plebeya. La Paz: Muela del Diablo.

Ticona, E., Rojas, G. \& Albó, X. (1995). Votos y Wipalas: Campesinos y pueblos originarios en democracia. La Paz: Fundación Milenio.

Toranzo, C. (2009). Visibilizar a los mestizos en Bolivia. En Crabtree, J., Molina, G. \& Whitehead, L. (Eds.). Tensiones irresueltas. Bolivia, pasado y presente. La Paz: PNUd/Plural.

Toranzo, C. (2006). Rostros de la democracia. Una mirada mestiza. La Paz: Plural.

Untoja Choque, F. (1991). Indigenismo, Indianismo y Katarismo. En Soria, S. (Comp.). Rebelión de un Qolla (pp. 105-101). La Paz: Fondo Editorial de los Diputados.

Untoja Choque, F. (1989). Proyección del Ayllu. En Soria, S. (Comp.). Rebelión de un Qolla (pp. 7-9). La Paz: Fondo Editorial de los Diputados.

Zapata, C. (2008). Los intelectuales indígenas y el pensamiento anticolonialista. Discursos/prácticas (2), 113-140.

Zavaleta Mercado, R. (1986). Lo nacional popular. La Paz: Los Amigos del Libro.

Recibido el 9 de julio de 2014. Aceptado el 3 de junio de 2015. 